\title{
Cluster Pattern Poincaré in Heart Rate Variability Due to Some Low Voltage QRS Complexes: A Rare Case
}

\author{
Rajani Bala Jasrotia ${ }^{1}$, Pramita Dubey ${ }^{1, *}$, Arvind Kanchan ${ }^{2}$, Nitin Ashok John ${ }^{1}$
}

\section{Rajani Bala Jasrotia ${ }^{1}$, Pramita Dubey ${ }^{1, *}$, Arvind Kanchan ${ }^{2}$, Nitin Ashok John ${ }^{1}$}

'Department of Physiology, Dr. Ram Manohar Lohia Institute of Medical Sciences, Lucknow, Uttar Pradesh, INDIA.

${ }^{2}$ Department of Physiology, Hind Institute of Medical Sciences,

Safedabad, Barabanki, Uttar Pradesh, INDIA.

\section{*Correspondence}

\section{Dr. Pramita Dubey}

Academic Block, Department of Physiology, Dr. Ram Manohar Lohia Institute of Medical Sciences, Vibhutikhand, Gomtinagar-226010, Lucknow, Uttar Pradesh, INDIA.

Phone: +91 9454191974

Email: pramita3107@gmail.com

\section{History}

- Submission Date: 18-08-2020;

- Review completed: 17-09-2020;

- Accepted Date: 28-09-2020.

DOI : 10.5530/ijcep.2020.7.3.29

Article Available online

http://www.ijcep.org

\section{Copyright}

(C) 2020 Phcog.Net. This is an openaccess article distributed under the terms of the Creative Commons Attribution 4.0 International license.

\begin{abstract}
Heart rate variability (HRV) is sensitive to the changes of the autonomic activity and decreases in looming morbidity of cardiovascular system due to autonomic dysfunction. In heart block or atrial flutter or atrial tachycardia, HRV with high power reported with cluster pattern on Poincaré plot which could be due to low voltage QRS complex beats which were not picked by software for HRV analysis. Picking those beats using custom settings included the beats and reported true HRV of the patient reflecting autonomic activity.

Key words: Cluster pattern, Heart rate variability, Low voltage QRS complexes, Poincaré plot, Software for HRV analysis.
\end{abstract}

\section{INTRODUCTION}

Heart rate variability (HRV) is a very sensitive marker for autonomic activity of the system. ${ }^{[1]}$ It usually decreases in impending morbidity of cardiovascular system due to autonomic dysfunction. ${ }^{[2]}$ A normal subject usually has a high HRV. ${ }^{[3]}$ Sometimes, HRV with very high power is reported. Such cases report cluster pattern on Poincaré plot. ${ }^{[4]}$ It is found in heart block or atrial flutter or atrial tachycardia. ${ }^{[4,5]}$ In this case, cluster pattern and very high HRV is found with no such cause. It was found to be due to some low voltage QRS complex beats which were not picked by software for HRV analysis. Picking those beats using custom settings included the beats and reported true HRV of the patient with torpedo pattern on Poincaré plot, reflecting autonomic activity.

\section{CASE REPORT}

This article reports a case, after proper consent, of 66 year old male who is a police subedar (a midlevel junior commissioned officer) who appeared for autonomic testing for Parkinsonism features. His Autonomic function test reports are mentioned in Table 1.

\section{DISCUSSION}

Heart rate variability (HRV) is a very sensitive marker for autonomic activity of the system. ${ }^{[1]}$ It usually decreases in impending morbidity of cardiovascular system due to autonomic dysfunction. ${ }^{[2]}$ A normal subject usually has a high HRV ${ }^{[3]}$ A high HRV can also be caused in conditions associated with Poincaré plot different from normal torpedo pattern for example, fan shaped Poincaré plots found in subjects with atrial fibrillation; multiple side lobe patterns found in atrial premature beats or ventricular premature beats; and an island pattern or cluster pattern in heart block, atrial flutter or atrial tachycardia. ${ }^{[4,5]}$ That is, a high HRV can sometimes signify a specific pathology if associated with a Poincaré plot apart from the normal torpedo pattern. ${ }^{[6]}$

\section{Table 1: Autonomic Function Test.}

\begin{tabular}{|c|c|}
\hline $\begin{array}{l}\text { Autonomic function } \\
\text { test parameter }\end{array}$ & Value \\
\hline $30: 15$ ratio & $\begin{array}{c}1.142 \text { (normal } \\
\text { parasympathetic response) }\end{array}$ \\
\hline Deep breathing ratio & $\begin{array}{c}1.85 \text { (normal parasympathetic } \\
\text { response) }\end{array}$ \\
\hline Valsalva ratio & $\begin{array}{c}1.27 \text { (borderline } \\
\text { parasympathetic response) }\end{array}$ \\
\hline $\begin{array}{l}\text { Diastolic Blood } \\
\text { pressure response to } \\
\text { sustained handgrip }\end{array}$ & $\begin{array}{l}<10 \mathrm{~mm} \mathrm{Hg} \text { (abnormal } \\
\text { sympathetic response) }\end{array}$ \\
\hline \multicolumn{2}{|c|}{ Heart rate variability parameters } \\
\hline Total power & $\begin{array}{c}6.755 \mathrm{e}+004 \text { millisecond } 2 \\
(\mathrm{~ms} 2)\end{array}$ \\
\hline Low frequency & $\begin{array}{c}1.204 \mathrm{e}+004 \text { millisecond } 2 \\
(\mathrm{~ms} 2)\end{array}$ \\
\hline High frequency & $\begin{array}{c}4.589 \mathrm{e}+004 \text { millisecond } 2 \\
(\mathrm{~ms} 2)\end{array}$ \\
\hline $\begin{array}{l}\text { Low frequency: High } \\
\text { frequency ratio }\end{array}$ & 0.2624 \\
\hline $\begin{array}{l}\text { Standard Deviation } 1 \\
\text { (SD1) }\end{array}$ & 287.7 millisecond $(\mathrm{ms})$ \\
\hline $\begin{array}{l}\text { Standard Deviation } 2 \\
\text { (SD2) }\end{array}$ & 257.6 millisecond (ms) \\
\hline
\end{tabular}

Cite this article: Jasrotia RB, Dubey $P$, Kanchan A, John NA. Cluster Pattern Poincaré in Heart Rate Variability Due to Some Low Voltage ORS Complexes: A Rare Case. Int J Clin Exp Physiol. 2020;7(3):122-4. 
In this case, a very high HRV was found (Table 1). Detailed analysis of the report revealed a cluster pattern in poincaré plot which was the cause of very high HRV. However, none of the causes could be found on ECG recording of the HRV which would cause cluster pattern, i.e, the patient neither had heart block or atrial flutter or atrial tachycardia.

Keenly observing the Electrocardiogram of HRV recording, it was found that some beats were not picked by the software as shown in the Figure 1(a). These beats were missed because of the low voltage of QRS complexes. The causes of low voltage complexes (voltage less than $5 \mathrm{~mm}$ in limb leads in all QRS complexes) can be hypothyroidism, obesity and pleural effusion. ${ }^{[7]}$ The patient had none of these morbidities. This patient

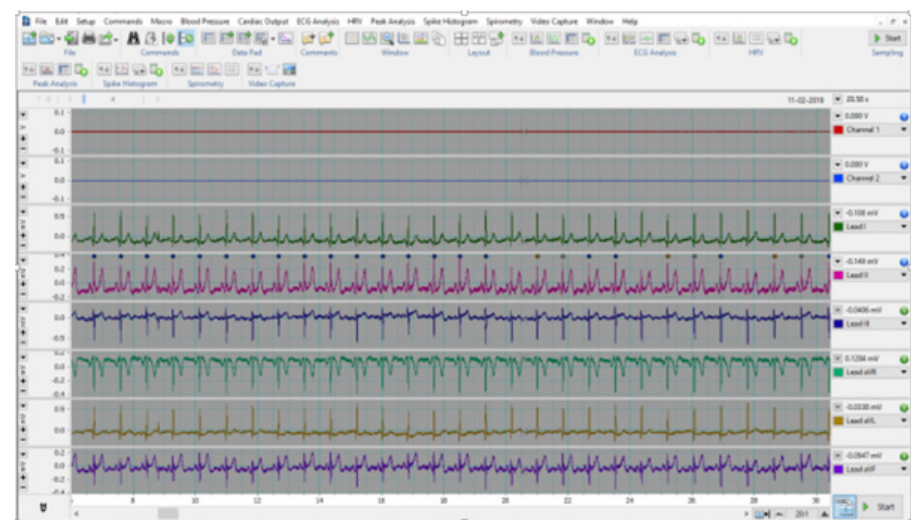

Figure 1(a): Beats not picked at around 20, 24, $28 \mathrm{sec}$.

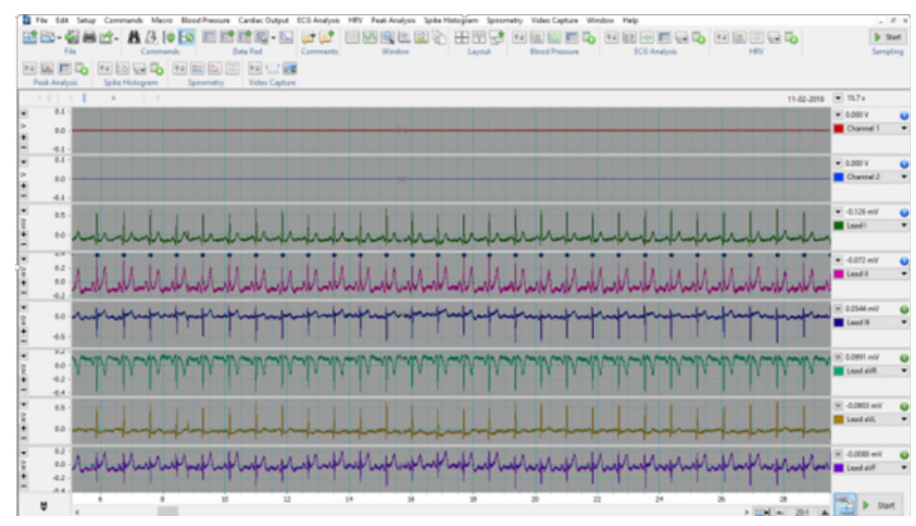

Figure 1(b): All beats picked after making changes in the settings.

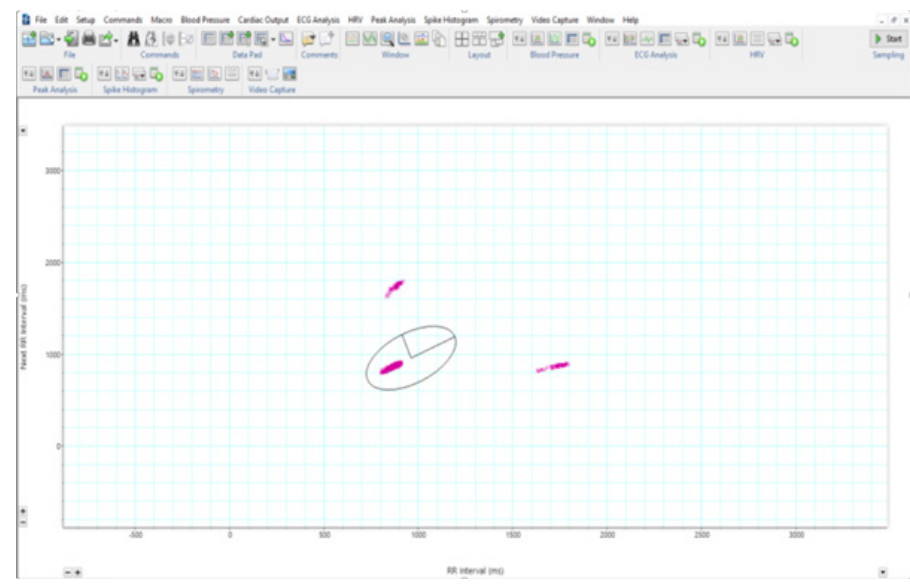

Figure 2 (a): Cluster pattern in Poincaré plot. was having low voltage QRS complexes in few beats only, the cause of which is not known. It could be a technical error. These low voltage QRS complexes caused the beats to be missed and therefore a spuriously high HRV with cluster pattern on poincaré plot [Figure 2(a)].

To find the actual HRV of this patient, threshold of wave to be identified as QRS complex was reduced from $3 \mathrm{mV}$ to $2 \mathrm{mV}$ using custom settings [Figure 2(b,c)]. This made all the low voltage QRS complex beats to be included in HRV analysis [Figure 1(b)]. Thus real HRV reflecting autonomic function of the patient was determined with a normal torpedo pattern on Poincaré [Figure 2(d)]. The HRV values now were: total power $410.5 \mathrm{~m} / \mathrm{s}^{2}$, Low frequency $56.73 \mathrm{~m} / \mathrm{s}^{2}$, High frequency 54.77

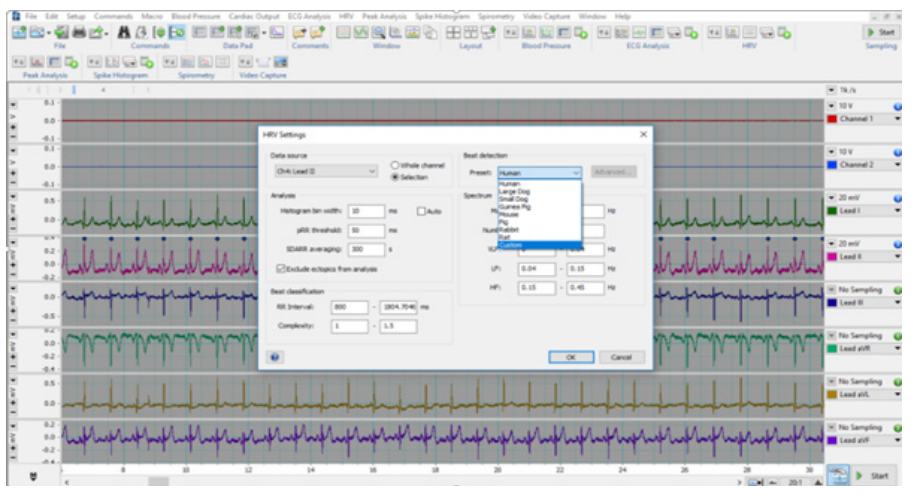

Figure 2 (b): Using custom settings to change QRS complex threshold from $3 \mathrm{mV}$ to $2 \mathrm{mV}$.

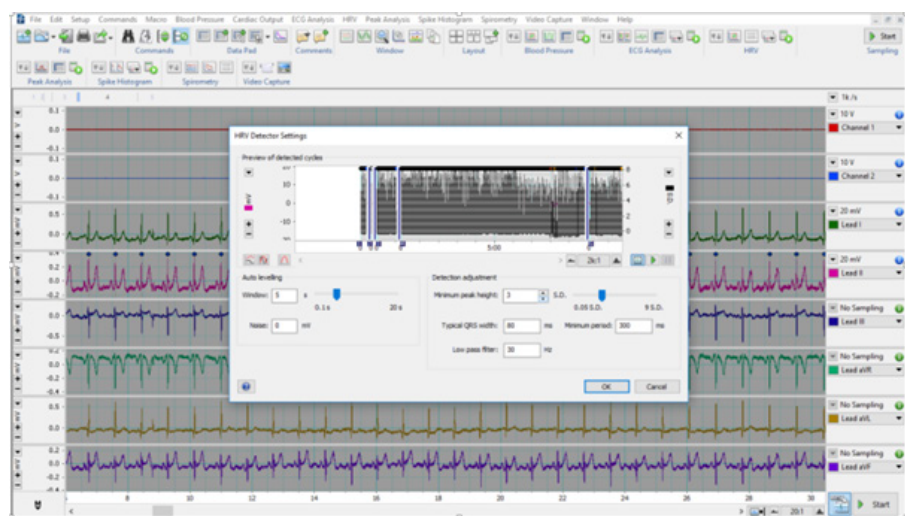

Figure 2 (c): Reducing threshold of QRS complex voltage.

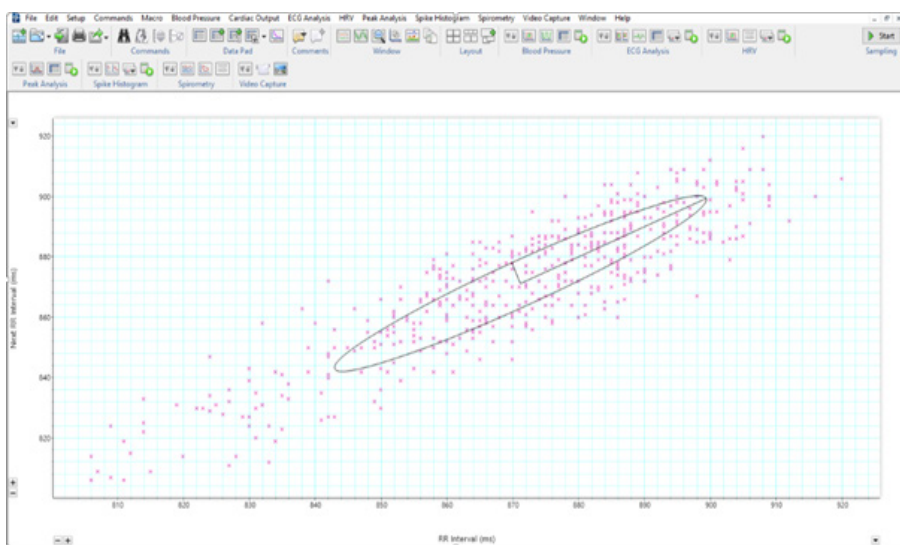

Figure 2 (d): Torpedo pattern on Poincaré plot obtained after making changes in settings. 
$\mathrm{m} / \mathrm{s}^{2}$, Low frequency: High frequency ratio 1.036, Standard deviation 1 7.53 milliseconds, Standard Deviation $230.75 \mathrm{~m} / \mathrm{s}$. Thus, the parameters were no more deranged to the previous extent and now reflect the autonomic activity.

It can be said that a very high HRV pattern can be caused by some technical error, which can be minimized by customizing the settings to get the real HRV of the patient. Poincaré plot should be first analyzed. If it is not a torpedo pattern, the cause should be looked in Electrocardiogram recording of HRV, else it may point to some technical error, which should be sort for.

\section{ACKNOWLEDGEMENT}

We would like to acknowledge Dr. Shweta Gupta, Senior resident, Dept of Physiology, Dr. Ram Manohar Lohia Institute of Medical Sciences, Lucknow for proof reading the article.

\section{ABBREVIATIONS}

HRV: Heart Rate Variability.

\section{REFERENCES}

1. Hye-Geum K, Eun-Jin C, Dai-Seg B, Young HL, Bon-Hoon K. Stress and Heart Rate Variability: A Meta-Analysis and Review of the Literature. Psychiatry Investig. 2018;15(3):235-45.

2. Francesco S, Valenzano A, Giovanni M, Giuseppe C, Vincenzo M, Gabriella M. Heart rate variability as predictive factor for sudden cardiac death. Aging. 2018; 10(2):166-77.

3. Shaffer F, Ginsberg JP. An Overview of Heart Rate Variability Metrics and Norms. Front Public Health. 2017;5:258.

4. Duong ND, Jeong H, Youn CH, Kim D. Development of new cluster descriptors for image analysis of Poincaré plots. World Congress on Medical Physics and Biomedical Engineering. Germany: Springer. 2009;

5. Gladuli A, Moïse NS, Hemsley SA, Otani NF. Poincaré plots and tachograms reveal beat patterning in sick sinus syndrome with supraventricular tachycardia and varying AV nodal block. J Vet Cardiol. 2011;13(1):63-70.

6. Dubey $P$, Verma $M$, John NA, Gutch $M$. Nonlinear parameter of heart rate variability can diagnose early cardiac autonomic neuropathy. J Arrhythmia. 2020;13

7. Tajiri J, Morita M, Higashi K, Fujii H, Nakamura N, Sato T. The cause of low voltage QRS complex in primary hypothyroidism. Pericardial effusion or thyroid hormone deficiency?. Jpn Heart J. 1985:26(4):539-47.

Cite this article: Jasrotia RB, Dubey P, Kanchan A, John NA. Cluster Pattern Poincaré in Heart Rate Variability Due to Some Low Voltage QRS Complexes: A Rare Case. Int J Clin Exp Physiol. 2020;7(3):122-4. 